\title{
Dumbbell-Shaped Intradiploic Epidermoid Cyst Involving the Dura Mater and Cerebellum
}

\author{
-Case Report- \\ Shinya ICHIMURA, Toshiyuki HAYASHI, Takahito YAZAKI, \\ Kazunari YOSHIDA, and Takeshi KAWASE \\ Department of Neurosurgery, Keio University School of Medicine, Tokyo
}

\begin{abstract}
A 55-year-old woman presented with an epidermoid cyst extending to the cerebellum manifesting as headaches and pain in the left eye. Magnetic resonance imaging showed an intradiploic part with ring enhancement and an intracerebellar part. Intraoperative inspection revealed erosion of the occipital bone and defective dura mater. The tumor was located both epidurally and subdurally and the cyst consisted of pearly white keratin. The tumor was totally removed and the patient was discharged with no neurological deficit. The intradiploic part of the tumor formed the body and the intracerebellar part was caused by inflammatory reaction, which resulted in the atypical enhancement of the intradiploic part.
\end{abstract}

Key words: intradiploic epidermoid cyst, dura mater, cerebellum, inflammatory reaction

\section{Introduction}

Intracranial epidermoid cysts are an uncommon tumor of the skull and account for only $1 \%$ of intracranial tumors. ${ }^{2,6,12,15)}$ Intracranial epidermoid cysts are usually located in the cerebellopontine angle and parasellar region, as well as the petrous apex, chiasmal region, brain stem, or intraventricular cavity. ${ }^{5,7)}$ About 25\% of central nervous system epidermoid cysts are intradiploic, ${ }^{1-5,9,10,12,13)}$ and about $3 \%$ of intradiploic epidermoid cysts extend to the subdural space. ${ }^{6)}$ Intracranial epidermoid cysts have a benign clinical and biological nature originating from the inner epithelial lining of the tumor capsule. ${ }^{2,5)}$ We report a case of intradiploic epidermoid cyst located both epidurally and subdurally with unusual ring enhancement on neuroimaging.

\section{Case Report}

A 55-year-old woman complaining of headaches and pain in the left eye visited a nearby hospital on November 2005. She was referred to our hospital for surgical treatment under a diagnosis of left cerebellar tumor. Physical and neurological examinations revealed no abnormalities.

Received June 5, 2007; Accepted November 20, 2007
Radiography of the skull showed a lytic lesion in the occipital bone (Fig. 1). Computed tomography (CT) demonstrated a low density mass with calcification in the inner table of the left posterior fossa (Fig. 2A). Bone window CT showed erosion in the inner table of the skull (Fig. 2B). $\mathrm{T}_{1}$-weighted magnetic resonance (MR) imaging with gadolinium showed the hypointense intradiploic part with ring enhance-

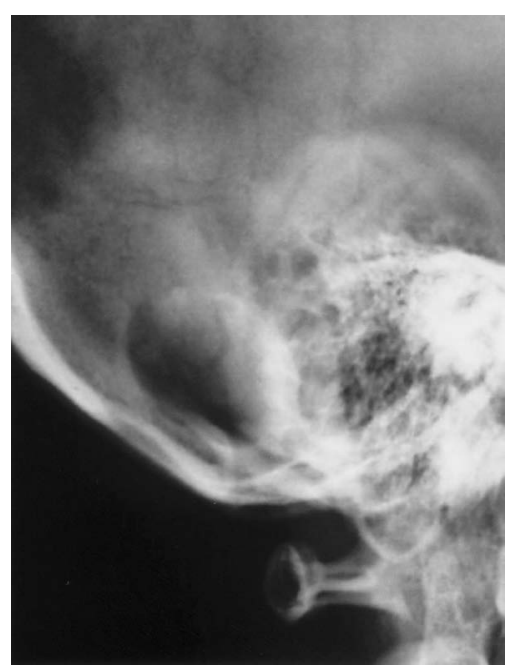

Fig. 1 Lateral skull radiograph showing an osteolytic lesion in the suboccipital area. 

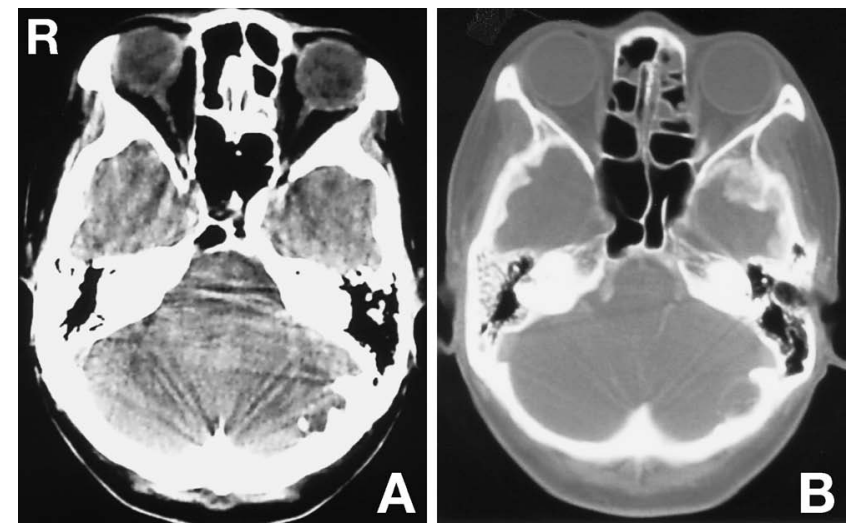

Fig. 2 A: Computed tomography (CT) scan showing a hypodense area with calcification in the inner table of the left posterior fossa. B: Bone window CT scan showing erosion in the inner table of the skull.
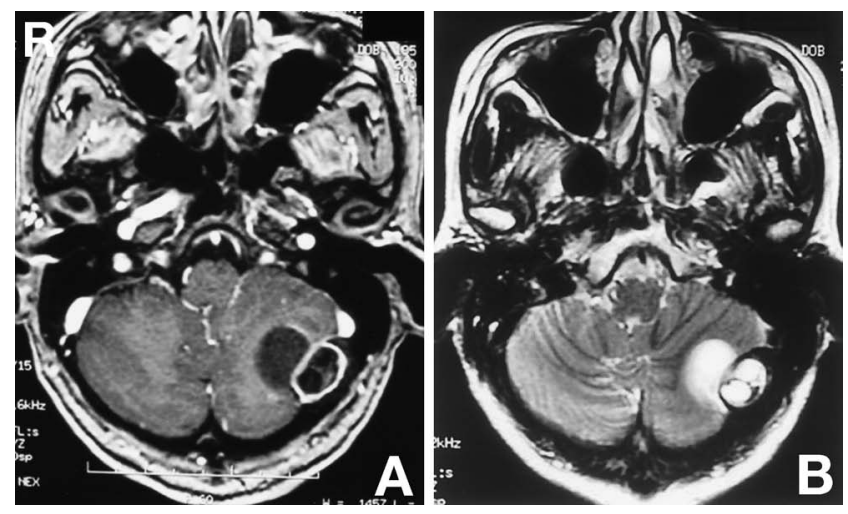

Fig. 3 A: $T_{1}$-weighted magnetic resonance (MR) image with gadolinium showing a dumbbell tumor consisting of an epidural part with rim enhancement and a subdural encapsulated part. B: $T_{2}$-weighted $M R$ image showing the intradiploic part with heterogeneous intensity and the intracerebellar part with high intensity.

ment and the intracerebellar part as hypointense (Fig. 3A). $\mathrm{T}_{2}$-weighted $\mathrm{MR}$ imaging showed the epidural part as hyperintense and the subdural part as hyperintense with extension to the cerebellum (Fig. 3B). Fluid-attenuated inversion recovery (FLAIR) and diffusion-weighted MR imaging were not done because epidermoid cyst was not suspected based on the configuration. The diagnosis was lowgrade glioma or parasite.

The patient underwent surgical removal of the tumor in February 2006. Intraoperative inspection revealed erosion of the occipital bone and defective

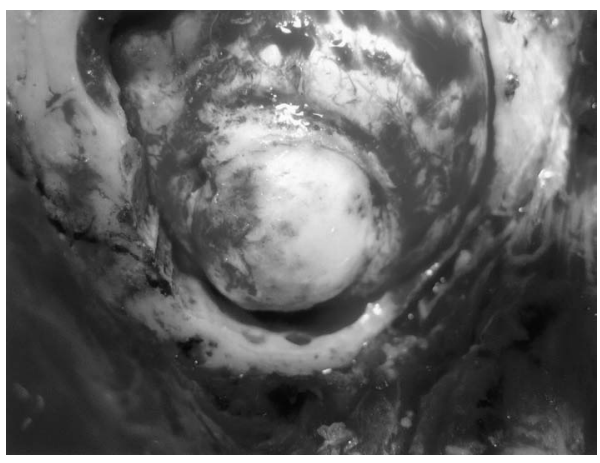

Fig. 4 Intraoperative photograph showing the tumor located both epidurally and subdurally, erosion of the occipital bone, defective dura mater, and calcification on the surface of the tumor.
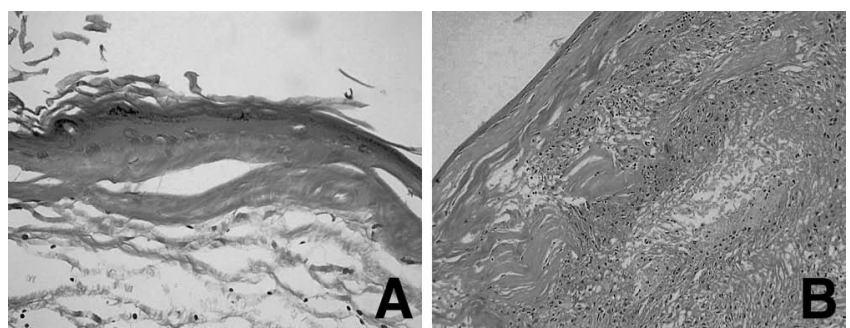

Fig. 5 Photomicrographs showing (A) the subdural part lined with flattened squamous epithelia and the cystic space filled with a large amount of keratinized debris, and (B) foreign body reaction and lymphocytic invasion in the epidural cyst wall. Hematoxylin and eosin stain, A: $\times 200, B: \times 20$.

dura mater, and calcification on the surface of the tumor (Fig. 4). The tumor originated from the diploe and extended to the cerebellum. The cystic wall was hypertrophic. The cyst consisted of pearly white keratin which was consistent with epidermoid cyst. The tumor was totally removed.

Histological examination revealed that the cyst was well-demarcated from the cerebellar parenchyma and no invasive growth was observed. The cystic wall was lined with flattened squamous epithelia without remarkable atypia, and the fibrous tissue beneath the epithelia was heavily hyalinized. The cystic space was filled with a large amount of keratinized material. No other component including immature nervous tissue was identified (Fig. 5A). Part of the cyst included foreign body reaction and lymphocytic invasion (Fig. 5B).

The postoperative course was uneventful and the patient was discharged without neurological deficit. 


\section{Discussion}

CT shows intracranial epidermoid cysts as sharply delineated low density lesions without enhancement after contrast injection. ${ }^{16)}$ Therefore, the CT diagnosis of intracranial epidermoid tumors is often difficult because of indistinct margins, close proximity to the skull base, and density similar to that of cerebrospinal fluid. ${ }^{14)} \mathrm{MR}$ imaging shows epidermoid cyst as hypointense on $\mathrm{T}_{1}$-weighted imaging without contrast enhancement, and hyperintense on $\mathrm{T}_{2}$-weighted imaging. ${ }^{5)}$ The chief advantages of $\mathrm{MR}$ imaging over CT are the three-dimensional definition of the cyst and the absence of skull base artifacts. ${ }^{11)}$

In the present case, the intradiploic part of the tumor formed the body containing keratin degradation which had the atypical appearance of low density on CT and heterogeneous intensity on MR imaging. We speculate that the intracerebellar part was caused by inflammatory reaction of the intradiploic part, because epidermoid cyst causes strong inflammatory reaction and histological examination detected foreign body reaction and lymphocytic invasion in part of the cystic wall. ${ }^{17)}$ This inflammatory reaction caused hypertrophy of the capsule and peripheral hyperostosis, observed as ring enhancement of the intradiploic part. The MR imaging intensities reflect the differences in the chemical composition of components such as cholesterol and keratin in the epidermoid tissue in addition to differences in the solid and liquid states of the tissue. ${ }^{8)}$ FLAIR and diffusion-weighted MR imaging may help to differentiate intracranial epidermoid cysts from other cystic intracerebral tumors, because epidermoid cysts appear as moderately hyperintense and hyperintense, respectively, on these sequences.

\section{References}

1) Arana E, Latorre FF, Revert A, Menor F, Riesgo P, Liano F, Diaz C: Intradiploic epidermoid cysts. Neuroradiology 38: 306-311, 1996

2) Berger Y, Srinivas V, Hajdu SI, Herr HW: Epidermoid cysts of the testis: role of conservative surgery. J Urol 134: 962-963, 1985

3) Bikmaz K, Cosar M, Bek S, Gokduman CA, Arslan M, Iplikcioglu AC: Intradiploic epidermoid cysts of the skull: a report of four cases. Clin Neurol Neurosurg 107: 262-267, 2005

4) Boyko OB, Scott JA, Muller J: Intradiploic epidermoid cyst of the skull: case report. Neuroradiology 36: 226-227, 1994
5) Chu CK, Tseng HM, Young YH: Clinical presentation of posterior fossa epidermoid cysts. Eur Arch Otorhinolaryngol 263: 548-551, 2006

6) Ciappetta P, Artico M, Salvati M, Raco A, Gagliardi FM: Intradiploic epidermoid cysts of the skull: report of 10 cases and review of the literature. Acta Neurochir (Wien) 102: 33-37, 1990

7) deSouza CE, deSouza R, da Costa S, Sperling N, Yoon TH, Abdelhamid MM, Sharma RR, Goel A: Cerebellopontine angle epidermoid cysts: a report on 30 cases. J Neurol Neurosurg Psychiatry 52: 986-990, 1989

8) Horowitz BL, Chari MV, James R, Bryan RN: MR of intracranial epidermoid tumors: correlation of in vivo imaging with in vitro $13 \mathrm{C}$ spectroscopy. AJNR Am J Neuroradiol 11: 299-302, 1990

9) Jaiswal AK, Mahapatra AK: Giant intradiploic epidermoid cysts of the skull. A report of eight cases. Br J Neurosurg 14: 225-228, 2000

10) Karadag D, Tuba Karagulle A, Erden A, Colpan E, Erden I, Caglar S, Erekul S: Post-traumatic intradiploic epidermoid cyst. A case report. J Neurosurg Sci 45: 224-227, 2001

11) Lunardi P, Missori P, Gagliardi FM, Fortuna A: Dermoid and epidermoid cysts of the midline in the posterior cranial fossa. Neurosurg Rev 15: 171-175, 1992

12) Nambu A, Imanishi $Y$, Iwasaki $Y$, Fujikawa $M$, Hayashi T, Shinagawa T, Araki T: Intradiploic epidermoid cyst with focal internal enhancement. Radiat Med 24: 224-227, 2006

13) Narlawar RS, Nagar A, Hira P, Raut AA: Intradiploic epidermoid cyst. J Postgrad Med 48: 213-214, 2002

14) Olson JJ, Beck DW, Crawford SC, Menezes AH: Comparative evaluation of intracranial epidermoid tumors with computed tomography and magnetic resonance imaging. Neurosurgery 21: 357-360, 1987

15) Smirniotopoulos JG, Chiechi MV: Teratomas, dermoids, and epidermoids of the head and neck. Radiographics 15: 1437-1455, 1995

16) Vinchon M, Pertuzon B, Lejeune JP, Assaker R, Pruvo JP, Christiaens JL: Intradural epidermoid cysts of the cerebellopontine angle: diagnosis and surgery. Neurosurgery 36: 52-57, 1995

17) Yamakawa K, Shitara N, Genka S, Manaka S, Takakura K: Clinical course and surgical prognosis of 33 cases of intracranial epidermoid tumors. Neurosurgery 24: 568-573, 1989

Address reprint requests to: Shinya Ichimura, M.D., Department of Neurosurgery, Keio University School of Medicine, 35 Shinano-machi, Shinjuku-ku, Tokyo 160-8582, Japan. e-mail: shinya3917@gmail.com 